\title{
Investigating the Academic Motivations of NCAA Gymnasts In and Out of Season
}

\author{
Amanda L. Paule-Koba, Ph.D. \\ Bowling Green State University \\ Maggie Dunn, M.S. \\ Florida State University
}

Abstract: As National Collegiate Athletic Association (NCAA) athlete exploitation has become a growing concern, it has become increasingly more important to examine the nature of how athletes are spending their time. The purpose of this study was to examine whether motivations change when Division I athletes are in season compared to out of season. A survey was distributed to Division I women's gymnastics teams from the Mid-American Conference (MAC). Results were assessed based on the factors of academic motivation and their differences during the varying times of the academic year. In this study, individuals from five MAC schools participated. It was concluded that, while academic motivations in season and out of season differed, there was not one season that was more academically demanding than the other. Participants reported feeling busier when in season, although being busy was not found to concretely impact their academics in negative ways. Participants were found to be motivated year-round by their own high expectations and wanting to decrease stress but were more motivated when in season to get ahead on academics to avoid having to focus on academics while traveling to away competitions. The findings are of note to the NCAA, athletic administrators, and academic advisors and should be considered when allocating resources to provide all athletes with academic support if the athlete, even high achieving athletes, feel it is needed to assist in attaining their academic goals.

Keywords: academics, athlete development, gymnastics, motivation

The National Collegiate Athletic Association (NCAA) currently has over 460,000 collegiate athletes participating in NCAA championship sports (NCAA, 2019). Through the years, the NCAA has coined the term "student-athlete" to refer to the undergraduate members who participate in both the academic and athletic sides of college. This term makes a point of putting the term "student" before "athlete," which emphasizes that the individual's main priority is education ahead of athletics (Saffici \& Pellegrino, 1998).

Being an athlete comes with many academic requirements, such as having to meet GPA benchmarks and having to meet certain percentages of a degree program at designated times in their academic career (NCAA, 2017). Many Division I institutions have entire academic support departments catered to solely helping athletes not only meet the minimum academic requirements set forth by the NCAA, but also to excel in the classroom and help athletes handle the busy lifestyle that the athlete has to manage. 
The entire premise of college is to prepare young adults for the future of having a career after their education is completed. Ultimately, the academic motivations of the collegiate athlete need to be examined to assess how to better serve this population. Determining the academic motivations and attitudes will uncover knowledge that can be used to help make academic programming decisions that can be implemented by athletic administration staff. These programs and/or tools can be used to better serve athletes and help them achieve their academic goals and stay motivated.

In season and out of season athletic time demands are different in nature. While preseason training implies an increase in the number of workouts per day or week, being in season requires the athletes to be away from campus while traveling to away competitions and games. When considering the demands placed on collegiate athletes, these factors "detract from the realistic likelihood of academic success, which in turn affects their academic motivation to succeed" (Simons, Van Rheenen, \& Covington, 1999, p. 151). Finding realistic time to dedicate to academics is a big problem among college athletes, since the pressure of their sport and keeping their athletic aid, for some, takes priority. While most athletes are competitive and can use this natural characteristic to translate into the classroom, this is not a general consensus for all athletes (Provencio, 2016). For some, "triggering the student-athlete identity on academic performance found that for some students it can be difficult to reconcile their athletic and student roles, causing deflated academic performance" (Provencio, 2016, p. 12).

Collegiate athletes are supposed to be a student first and athlete second, yet the dynamics of college athletics do not prove to support that reality. According to the NCAA, an athlete is allowed to spend a maximum of twenty hours per week on their sport (NCAA, 2016). However, this is rarely followed, and athletes are overworked in their sport (NCAA, 2016; Saffici \& Pellegrino, 1998), which leaves little time to devote to anything else. The NCAA (2016) GOALS report found there was a two hour increase in the number of hours dedicated to sport related activities per week from 2010 to 2015 . Athletes reported that they actually spent 32 hours per week on athletics during the 2010 year and this number increased to 34 hours per week on athletically related activities during the 2015 year (NCAA, 2016). This is far above the maximum that is imposed by NCAA rules. The athlete's academic career can suffer "due to the athletic department's attitudes of having to "win at all costs"” (Saffici \& Pellegrino, 1998, p. 4).

It is important to note that academic success also encompasses more than just the athlete's grade point average. Areas of personal development and life skill enhancement are integral components of the proficiencies that an undergraduate should be able to master as a result of their education (Gayles, 2009). While this study will focus on academic motivations, it is important to consider the broader definition of academia and learning when attempting to gauge if athletes are being enriched through sport participation.

Motivation comes in several forms and individuals absorb this motivation in different ways. This study will answer the ways in which sport contributes to academic success for Division I gymnasts in the Mid-American Conference (MAC). There is already evidence that supports that participation in intercollegiate athletics increases academic motivation and likelihood to complete a college degree (Gayles, 2009; Paule \& Gilson, 2010; Paule \& Gilson, 2011). Presently, the ways in which being immersed in the structured, high-pressure environment of a competitive season 
help to translate those focus skills into the classroom will be examined, as well as the impact which traveling on the weekend has on the academic stress placed on the athlete each week during their competitive season.

Female gymnasts were the population chosen for this study. It is important to recognize that the sport of gymnastics is comprised of both women and men. However, for this paper, only women's gymnasts are examined. Women's gymnastics garners the most media coverage once every four years when the Olympic Games televises the five gymnasts who make the team. The misconceptions of how the sport of gymnastics works are overwhelming. Many elite gymnasts will choose to go the NCAA gymnastics route, due to the decreased time demands, financial burden, and overall difficulty associated with NCAA gymnastics, as opposed to attempting to make an Olympic team. Currently, there are 62 schools that offer Division I gymnastics programs (i.e., Women's DI and DII Team Sites). The structure of elite, or Olympic, gymnastics and NCAA gymnastics is very different. This research will focus solely on NCAA gymnastics.

Collegiate gymnasts perform very well in the classroom year after year. The graduation success rate tracks degree completion for student-athletes, including those athletes who transfer to different institutions (NCAA, 2017). Of the MAC schools that sponsor gymnastics, Bowling Green State University, Central Michigan University, Eastern Michigan University, Kent State University, Northern Illinois University, and Western Michigan University all had perfect graduation success rate (GSR) scores of 100 during the 2016-2017 academic year (NCAA, 2017). This means that the MAC is successfully assisting its gymnastics student athletes to graduation each year. In the same academic year, 70 of the NCAA women's gymnastics teams recorded team grade point averages (GPAs) of a 3.0 or higher, and 24 of those team had over a 3.5 team GPA (NCAA Academic Rankings, 2018). The academic success of this sport is undeniable and made evident through the consistent and continuous academic awards and achievements recorded each year.

\section{Significance and Purpose of the Study}

This study is significant for several reasons. First, the majority of the research surrounding collegiate athletics and academics has primarily centered around athletes in revenue producing sports or those deemed at-risk academically. The population of this study is unique and can add additional insight into how athletes view and manage their academics.

The second significant reason for this study is that the mental health and well-being of athletes are incredibly important topics that are finally garnering attention in athletic departments across the country. This study will address the sources of stress that these athletes deal with on a daily basis.

Thus, the purpose of this study was to discover what the academic motivations are among collegiate gymnasts. The following research questions guided this study:

(a) Do academic motivations change when athletes are in season compared to out of season?

(b) What factors impact the athlete's ability to be academically motivated?

(c) What can stakeholders do to help academically motivate the athlete? 


\section{Review of Literature}

\section{NCAA Requirements}

The NCAA requires athletes to maintain certain academic standards to stay eligible for athletic competition, such as GPA benchmarks, full-time student status, progress towards degree completion, and fulfillment of a minimum of six-degree hours each term. The athlete must always be enrolled in enough credit hours per term that satisfy the full-time student requirement, which is 12 credit hours at most institutions. The exception to this rule is that if the athlete is in their last semester and plans to graduate, they do not need to be enrolled as a full-time student.

Athletes must also make progress toward the completion of their degree. By the end of the second year, athletes need to have completed a minimum of 40 percent of their degree program. By the end of the third year, they need to be at 60 percent of their degree program and reach 80 percent at the end of the fourth year (NCAA, 2017). The grade point average benchmarks differ based on the year that the athlete is in their academic career. As a freshman, the student must earn a minimum of a 1.8 GPA, a minimum of a 1.9 GPA after their second year, and maintain a 2.0 GPA every year after that (NCAA, 2017).

Along with GPA benchmarks, the current athletes need to pass six-degree hours per semester. All first-year students must pass a total of 18 credit hours between the fall and spring terms and 24 credit hours between the summer, fall, and spring semesters.

\section{Defining the Athletic "Season"}

An NCAA athlete experiences their sport from two major perspectives: in season competition and out of season training. To delve into the impact that the two season differences have on the academic attitudes of athletes, it is important to first define and uncover the differences. Each season offers advantages and disadvantages to the athlete due to the nature of the time commitments. Based on NCAA rule 17.1.7.2a from the NCAA Legislative Services Database (LSDBi):

Outside the playing season, from the institution's first day of classes of the academic year or September 15, whichever occurs earlier, to one week prior to the beginning of the institution's final examination period at the conclusion of the academic year, only a student-athlete's participation in required weight training, conditioning and skill-related instruction shall be permitted. A student-athlete's participation in such activities per Bylaw 17.02.1 shall be limited to a maximum of eight hours per week with not more than two hours per week spent on skill-related workouts. All countable related activities outside the playing season are prohibited one week prior to the beginning of the final examination period for the applicable academic term through the conclusion of each student-athlete's final exams. (2017, para. 1) 
Preseason practice falls under a different category of "out of season training." Once an athlete has entered a preseason training period, "an institution is not required to provide student-athletes with one day off per week during preseason practice that occurs prior to the first day of classes, or the first scheduled contest, whichever is earlier" (See NCAA bylaw 17.1.7.4.3, para. 1). These days off of training and competition are days that the athlete can use to either get caught up on schoolwork, or to get ahead of their schoolwork to decrease stresses about academics moving forwards. When these day offs are limited, the athlete loses this opportunity to dedicate a day to their education.

According to the NCAA, in season training is defined differently for each sport. Based on NCAA rule 17.1.1:

The playing (practice and competition) season for a particular sport is the period of time between the date of an institution's first officially recognized practice session and the date of the institution's last practice session or date of competition, whichever occurs later. (2017, para. 1)

The athlete is subject to traveling, late night competitions, and decreased amounts of free time and freedom to do what they wish. Coaches create itineraries for weekends that they are on the road, which often include time for schoolwork. With this increase in structure, the athlete is micromanaged and given little leeway to get off track in their athletics and academics. However, athletes may become overwhelmed with the expectations from coaches to excel in the academic and athletic arenas.

Although their time can be micromanaged by coaches while in season, there are limitations placed on their number of hours the athletes can participate in activities related to their membership on an athletic team. NCAA bylaw 17.1.7.1 state that during an athletic season, "a student-athlete's participation in countable athletically related activities (see Bylaw 17.02.1) shall be limited to a maximum of four hours per day and 20 hours per week" (NCAA, 2017, para. 42). The NCAA has laws in place to limit the amount of time the coaching staff can take from the student, but this is often taken advantage of through legislative loopholes and mandatory "volunteering." Realistically speaking, these athletes dedicate around "30-40 hours per week on their sport, which is mentally and physically exhausting, allowing them little time or energy to put toward their studies" (Saffici \& Pellegrino, 1998, p. 3).

NCAA Bylaw 17.1.6.6 is a year-round academic rule that states, "no class time shall be missed at any time (e.g., regular academic term, mini term, summer term) for practice activities except when a team is traveling to an away-from-home contest and the practice is in conjunction with the contest" (NCAA, 2017, p. 1). While this is difficult to track at times, the four hour maximum per day for training hours helps to ensure that the athlete is only required to commit time to their sport during their four-hour practice block and get to class on time. 


\section{General Athlete Attitudes}

Since the athlete population is segregated from the rest of the student body at many institutions, athletes at times feel out of place in the academic setting:

Whether by choice or as the result of influence from the athletic structure, studentathletes also live, eat, study, and socialize together, and are often tracked into the same majors, which leads, in part, to academic and social isolation from the rest of the campus community. (Comeaux, 2011, pp. 75-76)

As first year college students, athletes "hold more responsibilities than the non-athletic participating student, and it may be more difficult for them to transition through changes in athletic participation demands on top of the new social and academic changes" (Saffici \& Pellegrino, 1998, p. 3). Their status as a star athlete has a high value when their application is lacking in the academic standards needed to be admitted to the university. While being thrown into this atmosphere, an athlete's social identity is praised in the athletic sphere but is degraded in the classroom setting (Simons et al., 1999). Being in this environment leads athletes to have poor attitudes about school but positive attitudes about their athletic pursuits. While the premise of college is to earn a degree, there are athletes that believe that they are only enrolled in college to play their sport and use it as a springboard to other professional leagues after college.

\section{Motivations}

The will to complete certain tasks always stems from within the athlete. This is often referred to as motivation. By definition, motivation is the ability to move someone to do something, even when the task becomes difficult or challenging (Jang, Conradi, Mckenna, \& Jones, 2015). There are several sources of motivation that individuals can pull from to help them accomplish a goal or continue to keep working hard towards an achievement. Sources of motivation can be both intrinsic and extrinsic, meaning that there is not always just one driving force that contributes to motivation. This can stem from both tangible and intangible sources and incentives, and have varying degrees to which the factor motivates the individual to do something.

Internal factors contribute to the motivation that an individual has to complete certain tasks. When individuals participate in or choose to do activities without the enticement of external, tangible rewards, they are participating for intrinsic reasons (Pedersen, 2002). Some intrinsic motivations for participation include feelings of self-worth, enjoyment, excitement, fulfillment, self-esteem, and competence (Davies et al., 2015). A strong support system also contributes to how intrinsically motivated an individual is (Davies et al., 2015). These intangible rewards create a motivational factor that leads to reasons why individuals participate or not.

When considering motivation, especially internal motivation, several other factors need to be considered to get the full picture. According to Jang and colleagues (2015), attitude, interest, values, self-efficacy, self-concept, and goals are six other areas that should be studied. These six items build off of each other to create what we know as motivation, or the driving force to do a task. A person's attitude about a particular task will determine how they feel about completing it (Jang et al., 2015). Specifically, it refers to "a set of acquired feelings about reading that 
consistently predispose an individual to engage in or avoid reading" (Jang et al., 2015, p. 240). When a person's attitude is more positive, the motivation comes easier. An individual's attitude about something may be based off of how interested they are in the topic. Higher levels of interest will lead to a higher likelihood that something gets accomplished (Jang et al., 2015). A value is defined as "a set of acquired feelings about [topics] that consistently predispose an individual to engage in or avoid [tasks]" (Jang et al., 2015, p. 240), meaning that how highly an individual values an item relates to how motivated they will be.

Self-efficacy, or "an individual's judgment of his or her ability to accomplish a specific task" (Jang et al., 2015, p. 240), refers to how confident the individual is in a certain area. Higher levels of confidence relate to higher levels of comfortability, leading to more motivation. Likewise, self-concept is defined as "an individual's overall self-perception [of the task], including his or her sense of competence and the role ascribed to [the task] as a part of his or her personal identity" (Jang et al., 2015, p. 240). The individual will be more motivated if they feel a connection to the task. The goal of the individual is extremely important in that it gives the individual a reason to be motivated and strive for (Jang et al., 2015).

External factors that serve a motivational purpose are known as extrinsic factors. This motivation can be seen as the external, tangible rewards that individuals receive as a result of participation in a certain task (Pedersen, 2002). Extrinsic motivations are considered to be a type of behavioristic approach (Pedersen, 2002) taken by others. Many behaviors seen in sport are considered to be "extrinsic reinforcements, including verbal and nonverbal reinforcements, verbal and nonverbal punishments, instructions, recognition, and feedback, are given" (Pedersen, 2002, p. 459).

Examples of these types of motivating factors include monetary rewards, job promotions, medals, or starting lineup spots. While extrinsic motivations work hand in hand with intrinsic motivations, in the sport context, "extrinsic rewards can over justify the sport behavior of children and in the process undermine their intrinsic motivations" (Pedersen, 2002, p. 460). In the NCAA college setting, external motivating factors may include earning lineup spots, earning athletic scholarships, and earning All-Conference or All-American Honors. Academically, All Conference Academic team honors, Dean's List, or graduate school acceptances may extrinsically motivate athletes to do well and stay motivated in the classroom.

Athletic motivation can consist of a combination of both extrinsic and intrinsic motivating factors (Pedersen, 2002). Their motivation factors are also unique to the sport population at times. According to Pedersen (2002), some reasons for sport participation include "having fun, skill improvement, fitness benefits, team interaction, sportsmanship, excitement, challenge, travel, trophies, media exposure, [and] wearing a uniform" (p. 461). While not every athlete experiences motivation on the same level, the act of competing on a team is a leading factor. Buning and Thompson (2015) found that athletes described "primarily being motivated to play for their current team for reasons associated with: (a) value placed on relationships with teammates, (b) excitement or enjoyment of the sport itself, and (c) to win or be the best" (p. 352). These answers indicate a mixture of both intrinsic and extrinsic motivational factors that athletes experience. 
In reality, there is scant academic research on the high achieving student. The needs of the achieving students are overlooked since they are not technically at risk for failing. Athletes who excel in the classroom still have to dedicate more than 20 hours each week to their athletics, they still travel on the weekends for away games, and they still have to meet high expectations just like any other athlete. Even though this group values school, it does not always mean that they are equipped with the necessary tools to actually be successful

\section{Method}

\section{Participants}

The participants in this study were members of a Division I Mid-American Conference (MAC) gymnastics team during the 2017-18 season. The graduating seniors and new freshmen were excluded from the study. Freshmen were excluded because they had not yet experienced a full academic year as an athlete. Seniors were excluded because they had since graduated from their gymnastics programs and institutions. Gymnasts from two universities within the MAC were excluded from this study due to the fact that their email addresses were not available or accessible through their institution's online public database. The decision to contact athletes directly and not go through the coaches or university was made to eliminate any influence outsiders could have on the participants responses. Surveys were sent out to 61 potential participants via email. Thirtyeight individuals completed the survey, which resulted in a participant response rate of $62.3 \%$.

Eighteen of the participants $(47.37 \%)$ fell in the $18-20$ years old age range while 20 participants $(52.63 \%)$ stated they were in the $21-23$ age range category. There were nine secondyear students, 18 third-year students, 10 fourth-year students, and one fifth year student that participated in the study.

\section{Instrumentation}

To gather and collect data, a 22-question survey was used. A survey was developed by researchers and pilot tested on a group of athletes that were not a part of the study sample. The survey began with a series of demographic questions (i.e., age, grade level, institution, academic major, GPA). These questions were added to gauge the background of each participant and what their academic level was at the time of survey competition. The next set of questions asked the participant to rate, on a scale of 1-5, their views on academics in certain settings. Examples of questions in this section included: "I feel more motivated to get ahead on my schoolwork when I know I have to travel on the weekend" and "Having more free time makes me push my schoolwork off." The purpose behind adding these rating-type questions was to help put the participant in different mindsets to assess how their motivations differ within the various settings. The survey ended with open response questions, which included questions such as "Please list three main factors that motivate you to do your schoolwork," "What are programs or steps that can be taken by your school's administration to improve your academic motivation," and "How does being busy impact your motivation to succeed in the classroom?" These questions allowed participants to add any academic motivations not previously listed under the multiple-choice section, expand on what they thought they could benefit from with increased motivation and academic success, and assess which season they felt they performed better academically. The data were analyzed based on 
motivations, the settings/season where motivation was found to be experienced at an increased rate, and "next steps" offered for administrators.

\section{Data Analysis}

The data were analyzed using data report exported from the Qualtrics database. Multiple choice questions were created into data charts and tables that outlined the results in numbers, percentages, and bar graphs. Additionally, chi-squared goodness of fit tests were used to determine if the expected value differed from the expected value (Vincent \& Weir, 2012).

The open-ended questions were using Patton's (2015) inductive method. The authors worked through the responses to develop lower order themes (Patton, 2015). After reaching a consensus and identifying "repeated" themes, the answers were broken down and separated based on factor 1 , factor 2 , and factor 3 groupings. The researchers counted the frequency of each repeated answer/lower order theme, then ordered them from the highest number of repeated answers to the lowest. This was then repeated for factors 2 and 3. Date were compiled into one master list to assess the overall factors of motivation.

\section{Results}

\section{Gymnastics Participation}

A series of questions were asked to gauge the culture that the participants experienced around academics in their current reality. The beginning of the survey asked if the participant felt that their participation in gymnastics made an impact on the major that they choose. When asked if their gymnastics participation impacted their choice of major, 32.43\% of participants reported that it did, in fact, impact the decision-making process on picking a college major, while $59.46 \%$ claimed that it did not. Only $8.11 \%$ reported that their gymnastics participation may have had an impact on their choice of major. This question did not allow the participant the opportunity to elaborate on if their gymnastics participation positively or negatively impacted their major decision. In regard to which season (i.e., in their competitive season or during their off season) the participants preferred to take a more challenging course load, only $5.41 \%$ reported they preferred to have more challenging classes during their competitive season. $94.59 \%$ of participants reported that they prefer to take a more challenging course load out of their competitive season while they were in their off season.

Participants were also asked to reflect upon how they felt their gymnastics participation impacted their academics. It was found that gymnastics participation had both positive and negative impacts on the participants, but the results of this study were overwhelmingly in favor of the positive impacts. Twenty-five of the participants felt that their gymnastics participation had a positive impact on their academics for a variety of reasons. Many cited the use of time management skills, discipline learned at a young age, and prioritization skills as main reasons for their success. Several noted wanting to succeed for the sake of their teammates and coaches, as well as representing their program in a positive light beyond their athletic role. Two participants felt that lack of time and emphasis placed on academics, and too much time spent on their sport, negatively impacted their academic performance. Two more participants reported mixed feelings about their 
sport participation in that they did their best to stay on track, but that the schedule required of them as an athlete made them fall behind on academics at times.

\section{Getting Ahead}

When analyzing if participants preferred to get ahead on schoolwork when they were in season compared to when they were out of season, it was found that three participants rarely liked to get ahead on their schoolwork during season. Seven participants reported that they sometimes preferred to get ahead on their schoolwork when they were in season. Fifteen participants reported that they often got ahead, while 13 participants reported that they always preferred to get ahead on their schoolwork during season.

While running data analysis, a chi-squared goodness of fit test was performed, therefore the data for column 1 (answer "never") was excluded. According to Vincent and Weir (2012), "the total number of frequencies $(\mathrm{N})$ should be at least 20, and the value of each cell in the expected frequencies row should not be less than 1" (p. 277). Based on this information, given that column 1 has a cell value of 0 , the date were excluded. After performing a goodness of fit test, the calculated value was 9.577. Using the values of Chi Squared distribution table with an alpha value of 0.05 , the critical value was calculated to be 7.815 . Since the calculated value was found to be greater than the critical value, the results are considered to be significant and in line with the predicted values. It is significant that 28 athletes preferred to get ahead on their schoolwork compared to the 10 who did not make it a priority.

\section{Academic Honors}

When examining if the idea of receiving academic honors (e.g., Academic All American, All Conference, etc.) helped push them to be academically motivated, it was found that five gymnasts rarely felt motivated by the idea of receiving academic honors, while 13 participants reported that they were sometimes academically motivated by these honors. Eight and 12 participants, respectively, reported to be often or always motivated by the idea of being able to earn academic honors respectively. While running data analysis, a chi-squared goodness of fit test was performed, therefore the data for column 1 (answer "never") was excluded based on findings from Vincent and Weir (2012). After performing a chi squared goodness of fit test, the calculated value was 4.313. Using the values of Chi Squared distribution table with an alpha value of 0.05 , the critical value was calculated to be 7.815 . Since the calculated value was found to be less than the critical value, the results are not considered to be significant, meaning that there was no significant statistical difference found between academic motivations and receiving academic honors.

\section{Time Demands}

Time demands were also investigated through the assessment of how busy the participating gymnasts felt. In terms of feeling busy, gymnasts in the study reported feeling the busiest when they were in season, as opposed to when they were out of season (see Figures 1 and 2 below). It was found that $71.05 \%$ of participants reported that they always felt busy during their competitive season, while $23 \%$ reported that they often felt busy during their season. When considering the off 
season, $23.68 \%$ of participants reported that they sometimes felt busy in the off season. Forty two point eleven percent and $31.58 \%$ of the participant pool reported that they often and always felt busy when they were out of season.

While running data analysis, a chi-squared test of independence was performed, therefore the data for column 1 (answer "never") was excluded based on findings from Vincent and Weir (2012). After performing a goodness of fit test, the calculated value was 14.16. Using the values of Chi Squared distribution table with an alpha value of 0.05 , the critical value was calculated to be 7.815. Since the calculated value was found to be greater than the critical value, the results are considered to be significant. In can be concluded that gymnasts in this study felt the busiest when they were in season.

Figure 1. When I am in season, I feel busy.

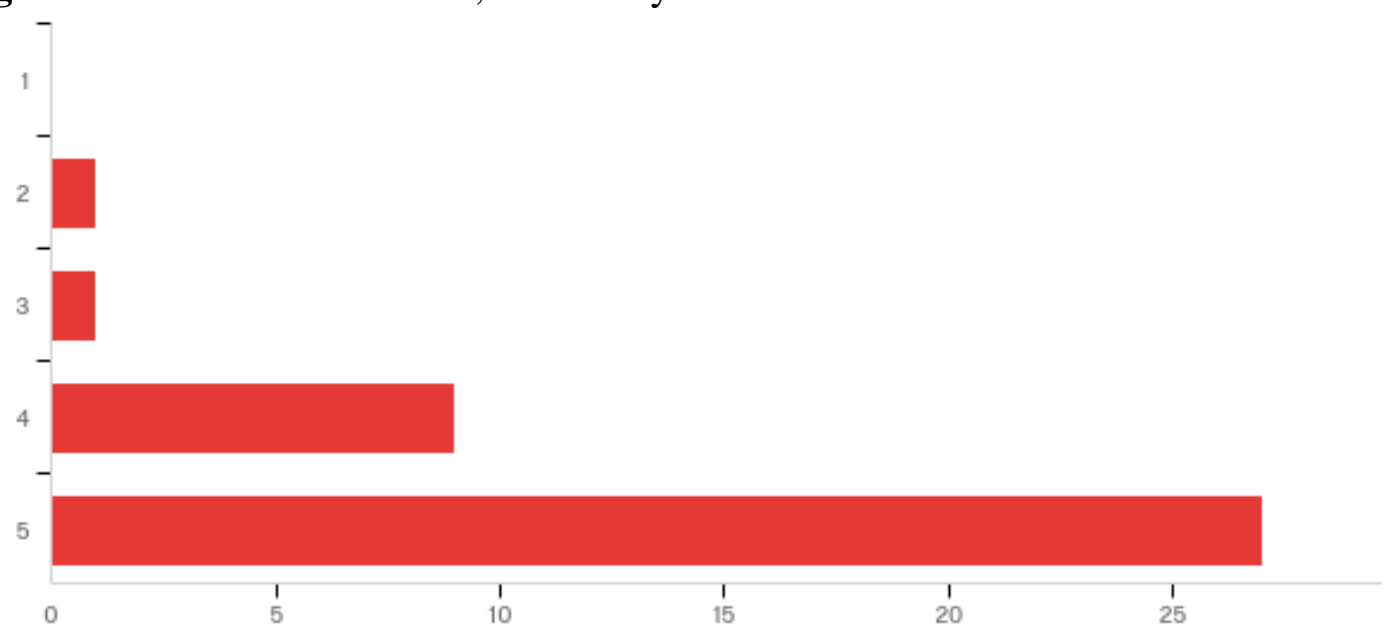

Figure 1. 1- never 2- rarely 3- sometimes 4- often 5- always.

Figure 2. When I am out of season, I feel busy.

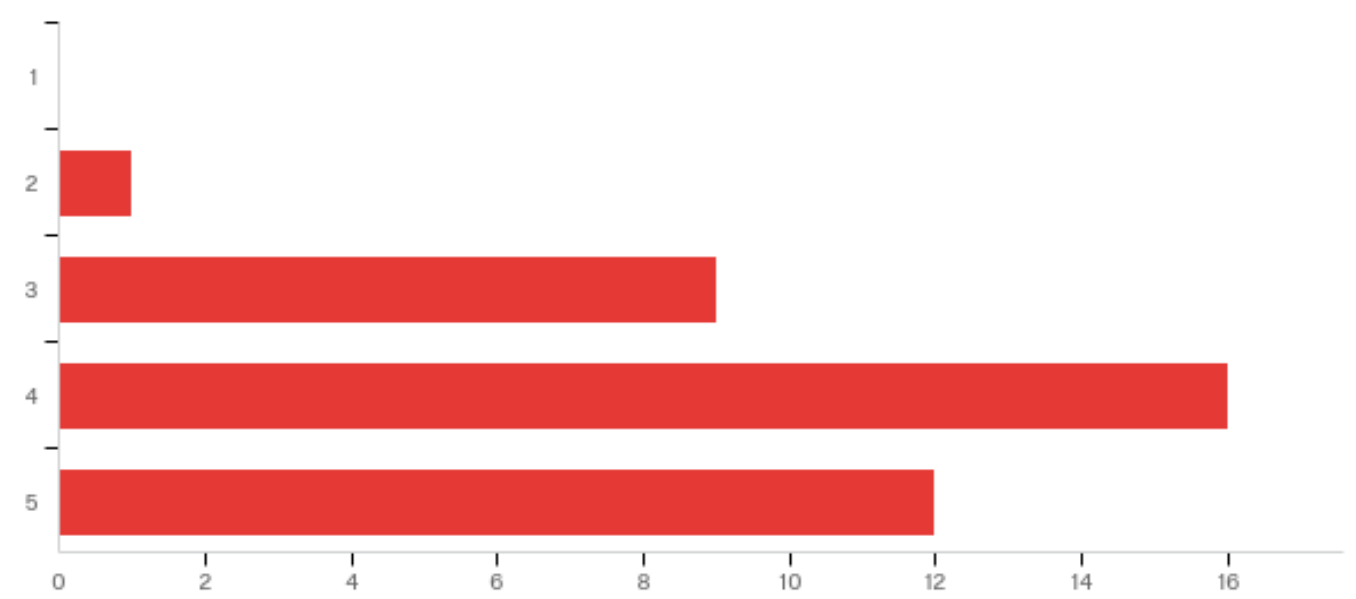

Figure 2. 1- never 2- rarely 3- sometimes 4- often 5- always. 
Figure 3. Having more free time makes me avoid completing my schoolwork.

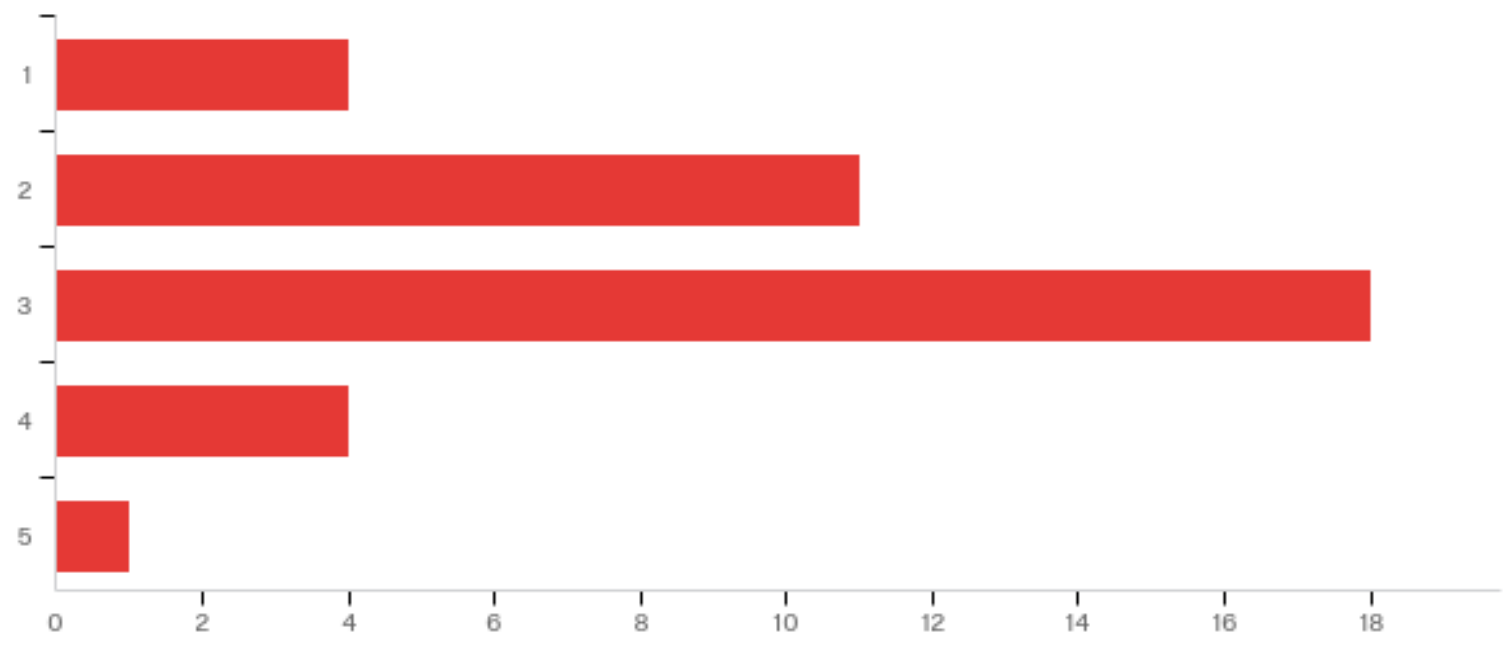

Figure 3. 1- never 2- rarely 3- sometimes 4- often 5- always.

The study asked the participants to reflect on whether more free time in their day makes them more likely to avoid or put off their schoolwork, which can be seen in Figure 3. Four participants stated that this was never a mindset that they had. Eleven participants reported that they rarely avoided completing their work when they had more free time, while 18 participants $(47.37 \%)$ admitted that sometimes having more free time made them avoid their academics. It was seen that four participants $(10.53 \%)$ felt that they often avoided their schoolwork when they had more time to complete it, and one individual stated that they always put off their academics when they had more free time. While running data analysis, a chi-squared goodness of fit test was performed. After performing a goodness of fit test, the calculated value was 25.34. Using the values of Chi Squared distribution table with an alpha value of 0.05 , the critical value was calculated to be 9.488. Since the calculated value was found to be greater than the critical value, the results are considered to be significant. It is important to note that based on this result, having more free time did not necessarily correlate to increased academic productivity.

Participants were also allowed to select all of the answers that they identified with when they felt busy. Based on the results, a majority of the participants reported that they used to-do lists and attempted to get ahead on their schoolwork when they felt that they were experiencing a busy time in their life. Nineteen participants $(50 \%)$ stated that when they were busy, they used "to-do" lists to plan out their time. Also, 16 participants (43\%) reported that they made sure to get ahead whenever they could when they were feeling busy. Only 3 participants (7.89\%) stated that when they began to feel busy, they started to fall behind on their responsibilities.

The relationship between being busy and the ability to succeed in the classroom was also addressed. Being busy was shown to impact the participants both positively and negatively. For some, being busy led to them being more focused, more intentional in how they spent their time, and more willing to work ahead on schoolwork throughout the week. These participants found that being busy decreased procrastination, increased time management, and decreased stress on the weekends. One participant reported that they were willing to work ahead during the week so that 
they could focus solely on their gymnastics responsibilities on the weekends during their competitive season. On the contrary, being busy also negatively impacted some participants. Some reported that they prioritized sleep and rest when they became busy, therefore academics became difficult to focus on. The lack of ability to complete a self-care routine was a repeated answer based on the busy schedule of the participants. It was also reported that the participants felt that they were unable to give their best effort in the classroom when they became overwhelmingly busy because athletics is seen as the priority.

\section{Motivations}

The survey asked participants if they felt more motivated to get ahead on their academic work when they knew they had to travel to away competitions during their competitive season. It was seen that three participants (7.89\%) answered that they rarely as well as sometimes felt motivated to get ahead when they knew they had to travel on the weekends. Fourteen participants, or $36.84 \%$, reported that they often felt motivated to get ahead on their schoolwork while in season, and $18(47.37 \%)$, reported that they always felt more motivated to get ahead on their schoolwork when they knew they had to travel on the weekend to competitions. While running data analysis, a chi-squared goodness of fit test was performed, therefore, again, the data for column 1 (answer "never") was excluded based on findings from Vincent and Weir (2012). After performing a goodness of fit test, the calculated value was 18.63. Using the values of Chi Squared distribution table with an alpha value of 0.05 , the critical value was calculated to be 7.815 . Since the calculated value was found to be greater than the critical value, there was a statistical significance found between being motivated to complete academics and having to travel on the weekends for away competitions.

Participants were asked to list the three main factors that they felt were the driving forces behind their academic motivation. Out of a list of 108 total factors, 12 repeated themes emerged. The 12 main themes are as follows: earning a high GPA/good grades, getting into graduate or professional schools, being a perfectionist/having high standards, avoiding stress/feeling busy, better future or career, sport or team expectations, love of learning, graduation, family, feeling proud of oneself, academic honors, and being eligible or passing classes.

Overall, "earning a high GPA/good grades" was cited the most at 23 times, "getting into graduate or professional schools" was second, being reported 13 times, "being a perfectionist/having high standards" was cited 11 times, and "avoiding stress/feeling busy" and "having the opportunity for a better future or career" were both reported 10 times each. Additionally, "sport or team expectations" was reported nine times, "love of learning" and "graduation" were each cited six times, "family" and "feeling proud of oneself" were each reported four times, and "academic honors" and "being eligible and passing classes" were cited three times each.

When analyzing what was reported for the first main factor in the athlete's academic motivation, maintaining a "high GPA" and earning acceptable grades was a very high response with 15 participants placing importance on this. The second factor repeatedly mentioned six times in factor 1 was the idea of "getting into graduate or professional school" after graduation. Setting themselves up for a "better future and career" after their undergraduate experience was also 
reported four times in factor 1. "Sport or team expectations" were mentioned three times, while "avoiding stress/feeling busy" and "being a perfectionist/having high standards" were mentioned twice each. "Being eligible/passing classes," "time management," "self-motivation," and "sleep" were each mentioned one time in factor 1. "Academic honors," "feeling proud of oneself," "love of learning," "graduation," and "family were not mentioned in the first factor."

The second reported factors in an athlete's academic motivation had a more even distribution of responses. At the top, "maintaining a high GPA and earning acceptable grades" and "being a perfectionist/having high standards" were both reported five times each. "Getting into graduate or professional schools," "setting themselves up for a better future and career," and "love of learning" were cited four times each in factor two, and "avoiding stress/feeling busy" and "graduation" were cited three times each.

The third reported factors were "avoiding stress/being busy" was cited the most at five times, followed by being a "perfectionist/having high standards," "sport or team expectations" that both recorded four responses each. "Earning a high GPA/good grades," "getting into graduate or professional schools," and "graduation" were each mentioned three times, while "better future or career," "academic honors," "feeling proud of oneself," "love of learning," "family," and "being eligible or passing classes" were all mentioned twice each. "Academic advisor" and "sleep" were factors that were each mentioned one time.

\section{Coach Involvement}

The survey also asked participants if they felt that their coaches placed a high emphasis on academic performance. Twenty-one of the participants $(53.8 \%)$ reported that they felt that their coaching staff always placed a high emphasis on how they were performing academically. There were four individuals in the study that felt that their coaches often placed a high emphasis on academics, while seven participants felt that their coaches only sometimes placed a high emphasis on academic performance. One person reported that their coaching staff rarely placed emphasis on academics, and another individual also said that their coaching staff never placed high emphasis on how they were performing academically. While running data analysis, a chi-squared goodness of fit test was performed. After performing a goodness of fit test, the calculated value was 12.849. Using the values of Chi Squared distribution table with an alpha value of 0.05 , the critical value was calculated to be 9.488 . Since the calculated value was found to be greater than the critical value, the relationship between having a supportive coaching staff who place emphasis on academics and academic performance is considered to be significant.

\section{Suggestions for Administration}

Participants were asked which programs or steps could be taken by their school's administration to improve their academic motivation. When asked about motivation, there were seven main themes that emerged in terms of what the participants felt that their administrators could do to help them improve their academic motivation. The answers that were reported were more study sessions, free tutoring and available academic advisors, less required study table hours, less emphasis placed on grades, incentives or rewards for academic achievements, motivation is intrinsic, and satisfaction with the efforts of their administration. With nine comments, the idea of 
having more incentives or rewards for academic success was thought to possibly increase academic motivations.

Participants believed that since the athletes come to college to be a student and get an education, they felt that their academic efforts should be highlighted and celebrated just as much as their athletic accomplishments. Five participants stated that they felt the administration could not do anything to help improve motivation, since motivation is an intrinsic quality. Four participants felt that the emphasis placed on homework and getting grades hindered their motivations; they preferred a more learning-based style to help increase their academic motivations. Two participants reported that offering more study session would assist them, while two other participants also stated that free tutoring services and available athletic academic advisors to help them would improve their motivations in the classroom. Two additional participants also reported that they felt that having less required study table hours would improve their motivation, while five participants were satisfied with their administration.

It was then asked which programs or steps could be taken by their school's administration to improve their academic performance. Six main suggestions emerged from asking the participants their opinions on academic performance. Six individuals reported that offering more tutoring, in a wide variety of subjects, would help them perform better academically. Two individuals suggested having a well-planned out-of-class schedule during their competitive season to decrease the amount of missed class time. Likewise, it was also suggested that meeting weekly with an athletic academic advisor in a more hands-on role to help plan out when to complete their work, when to study on the road, and to also help pick a better, more effective class schedule would improve academic performance.

In addition, two participants reported that better test preparation workshops to decrease test anxiety would be beneficial. Two more participants reported that having more genuine coach buyin to the importance of their academic careers would help improve classroom performance. This coach buy-in would allow athletes to concentrate on academics without fear of coaches having a negative reaction to their time spent with their textbooks and not in the gym.

Three participants felt that an incentive program that rewards academic performance would help to improve their own academic performance, while eight participants reported that they either did not feel that the administration could help improve their academic performance or they felt that their academic performance did not need to be improved. Other answers given were structured study table hours, an additional day off to focus solely on academics, allowing study hall hours to count at quiet places other than the academic center, reinforcement of basic concepts, less busy work, and increasing the minimum GPA requirements to compete.

\section{Discussion}

Analysis of the results of this study revealed that while the level of motivation and academic commitment did not vary much during in season and out of season, the stressors and threats to their motivation did differ based on the season. The incredible time commitment and the reality of balancing multiple required commitments was a large contributing factor. When in season, participants stated they were "always busy" in comparison to feeling "often busy" when 
they were out of season. This implies that this population feels very busy both while in season and during the off season but felt more overwhelmed while traveling in season. It is important to note that feeling less busy and having more free time did not necessarily relate to increases in motivation. It was found that having more free time led to participants pushing their responsibilities in the classroom aside, whereas when they felt busy, they reported to want to get ahead on academic tasks. They also reported feeling more motivated when they knew they had to travel on the weekend and used "to-do" lists to help organize their responsibilities. Likewise, several also reported that their NCAA gymnastics participation actually helped their overall approach to academics. They felt that gymnastics fostered skills and values such as accountability, time management, and an inner drive to want to earn the best grades they could. This is counter to Provencio's (2016) study that found that the time spent in season on their sport caused a decrease in academic performance.

The study also sought to uncover why motivational factors impact athletes in the way that they do. The top-rated factors were grades and GPA (accounting for more than half of the responses), graduate school, being a perfectionist, stress, future careers, and high sport expectations. While the reason behind these factors was not directly answered, it is important to make connections to what we now know.

It is already known that gymnastics is considered to be a high achieving sport in terms of their academics (Antonio Pineda-Espejel, et.al., 2016). Grades and GPAs were the top-rated factor contributing to their motivation levels. Since the majority of the sample was highly concerned with their future and continuing their education beyond their undergraduate career, grades will naturally be a motivating factor, since that is a benchmark used to measure certain jobs and professional program criteria. Being a perfectionist, as reported by 11 participants, will dictate how the individual operates. Perfectionism refers to an individual's propensity to set (and strive for) exceedingly high standards of personal performance in specific areas of their life (Gilman \& Ashby, 2006). Being motivated by the idea that everything has to be done to the best of their ability will have a connection to how much they are willing to get ahead on work and how much they are willing to push off to a later date.

Another area that was repeatedly mentioned was the idea of being motivated by academic honors or awards, and that the implementation of more programs to recognize the academic achievements of athletes would increase the drive to succeed. These external awards or recognitions are similar to what Pederson (2002) discussed when he examined motivations of athletes. He found that external motivations, such as awards, can increase motivation. Thus, for those high achieving athletes who want to excel in academics and athletics, academic awards and honors would be a great source of motivation. Additionally, this ties into the perfectionist tendency, where there is an award to be won and a benchmark to be met, the individual will not settle unless that goal is met. These perfectionist tendencies can be positive or negative in nature with the negative consequences potentially resulting in an individual having high stress levels or mental health issues (Anshel, Henry, \& Kim, 2009). 


\section{Importance for Change}

It has already been acknowledged, based on this sport being at the top of the NCAA GPA rankings year after year, that the sport of gymnastics is a very high academically achieving sport. Most of the athletes in this sport are good students, want to learn more about their field of study, and see the value of a college education. These characteristics were highly evident in the results. Simons et al. (1999) found that there are several aspects of college life that hinder the motivation for academic success, and while the motivation for academic success was evident in this population, the resources necessary for them to achieve that success in the classroom was lacking. These participants were willing to manage their time appropriately and value their education; therefore, their administration needs to match their academic needs with the proper programming and/or access to resources to assist the athletes in performing up to their potential.

The results of this study are important for a myriad of reasons. It uncovered the sources of both stress and academic motivation that NCAA Division I female gymnasts experience. It allowed researchers to offer suggestions as to what administrators can do to better serve this population based on the feedback given by the athletes themselves. These results displayed that even at the mid-major level, the NCAA is still not entirely serving the athletes in its highest capacity. There are still holes to be filled in improving the academic culture on some teams. Unfortunately, the sport requirements of the NCAA do not appear to limit their number of hours spent on athletics, based on the NCAA GOALS study (2016), and this has been seen to have negative impacts on academic success (Paule \& Gilson, 2011; Saffici \& Pellegrino, 1998), citing an even greater importance for enhanced academic support in terms of advising and tutoring services offered. That being said, there are still academic services to be enhanced within programs who do value the academic side of college sport, not just for the programs deemed an APR risk for the institutions athletic department. Mental well-being and stress still need to be examined to implement changes to these athletic programs. Such high emphasis is placed on the revenue generating sports, yet this study uncovered the need to also find time, resources, and value in helping those who may not generate the most money, but still dedicate their young adult life to representing the university at the national level.

Overall, the results showed that even amongst this high achieving population of collegiate athletes, there are still high concerns about academics. These athletes still claimed to not have enough time to devote to their academics. These participants reported feeling overwhelmed to the point of feeling they could not handle the stress. These participants, who value learning more than most other areas in their college career, still felt that their coaching staffs did not always support their academic pursuits. It is important to note that, as previously stated, gymnasts tend to be perfectionist, and perfectionists are individuals who have a "concern for errors, doubts on the execution of tasks" (Antonio Pineda-Espejel et.al., 2016, p. 272). As a perfectionist who feels they are lacking the necessary support to properly execute a task (i.e., classwork), this lack of support could be detrimental.

This research has proved to be relevant and necessary through the correlation it has with the NCAA GOALS Study findings from 2016. The NCAA found that athletes wanted certain programming that pertained to "academic success and especially preparing to get a job after college," as well as help with "balancing academics/athletics while keeping sports in perspective" 
(NCAA, 2016, p. 5). This research study found that similar programs were desired by this population of MAC gymnasts. They valued preparing for their future career as well as preparing for graduate school. MAC gymnasts also expressed difficulty balancing school and their sport. The results of both studies portray a clear picture of the need to focus NCAA resources and attention to providing academic support for all athletes.

\section{Implications for Administrators and Coaches}

Based on this research, it has become evident that even these academically high achieving athletes are feeling overly stressed, overwhelmed, and several even mentioned that they feel their current academic/athletic life is "too much" to handle at times. There are several steps, both big and small, that administrators can take to decrease the stress these athletes face to make balancing their lives seem more manageable.

First, the tutoring services offered to the athletes need to remain and be improved. While this will be dependent on budgets, it was suggested that more subjects be offered beyond the typical subjects that students normally take. In addition to subject tutoring, another service that could be helpful would be test preparation workshops to decrease test anxiety. Not athlete is as confident in the classroom as they are on the field or in the gym. In order to combat that lack of confidence, test preparation workshops ran by the athletic academic services office would be beneficial. Having the athletic academic services office offer these workshops would be advantageous because they can provide the programs at times when they know the athletes are free and in environments where the athletes feel comfortable.

Since travel is inevitable and coursework does not stop just because the athlete has an away game, more reliable academic resources need to be provided for those athletes by the university, which they are representing. It was cited that the Wi-Fi when traveling is not always reliable, which negatively impacts the athlete's ability to complete their classwork when on the road. Since working ahead is not always the solution or even an option for the student, administrators could enact one of two solutions to combat this issue. One proposed solution would be to ensure that the internet on the university bus used for travel is equipped with reliable service that the athletes can count on to use. Second, administrators could adopt a portable Internet device program in which the athletic department provides head coaches with one portable Internet router that teams can use while traveling for away competitions only. This would ensure that the coaching staff has control over the device, yet the athlete's academic performance would not suffer due to poor Internet access while not on their university's campus.

Another way that the coaching staff can help to improve academic motivations among their athletes would be to truly buy in to the academic culture of the university. While the athlete is definitely at their school to participate in athletics, the coaches need to find time and ways to place emphasis on the importance of academics. Based on the results of this study, having days off dedicated solely to academics (where athletes can go to the library, attend faculty office hours, or meet with classmates), and allowing for athletes to earn "study hours" at places other than their academic center (at their discretion) are two ways in which the coaches can show to their team that academics are important and should be taken seriously. Academics should not be negatively 
impacted by athletic participation, and action steps as such could lead to creating a better academic culture on their gymnastics teams.

\section{Implications for the NCAA}

The NCAA has taken a strong stance on two areas of athlete development and welfare. The NCAA stresses the idea that most of the NCAA athletes will not go on to play professionally after the conclusion of the athlete's college sport career. They stress the importance of developing the athlete beyond their sport and making sure the "student" aspect of the term "student-athlete" is heard. This notion of supporting athletes academically should be true for all sports, not just the ones deemed to be underperforming in the classroom. Even high achieving students need academic support, such as tutoring services and advising appointments. Based on this research study, which considered the opinions and experiences of current athletes, the NCAA should reconsider their stance on how they serve their athlete population as a whole. The NCAA should consider tailoring the types of support athletes receive to the individual and not apply a one-size fits all approach to athletes. This could assist athletes in achieving their maximum academic potential. This current state of NCAA academics is not reflective of the mission of the NCAA as a whole.

Another large mission that the NCAA operates with is working towards creating a better mental health climate for athletes, as well as creating programming to both help recognize poor mental health signs and ways to assist those who are struggling. This research uncovered the need to look at the role that academics plays on mental health issues among athletes. There were participants who, when asked to describe academics in one word used "stressed," "overwhelming," and "too much" as their views on academics. The participants are considered to be some of the highest achieving in the NCAA, yet they feel like they do not have enough support regarding their academics to the point where they feel that they cannot handle it. Similar to the allocating of resources suggested above, attention needs to be allocated equitably too. Just because sports like gymnastics are not an eligibility or an APR concern for universities, the NCAA must still find a way to provide financial support for their member institutions to be able to support all athletes. When the support is lacking in the academic area, the stress levels rise, leading to increases in anxiety and decreases in mental stability among this special population on college campuses.

\section{Limitations of the Study and Future Research}

There were several limitations to this study that were identified. First, the study excluded every male sport and their perspective on academics. Second, the only sport considered was gymnastics, which not only excludes information from every other sport, but the perspective of an athlete whose competitive season is in the fall semester instead of the spring. On top of this, because they have not yet experienced a full competitive season with the NCAA at the time that the data were being collected, current first year students were also excluded from this study to help ensure accuracy in answers.

Future research studies should examine male gymnast perspectives of academics. It would be interesting to see how their perspectives are similar or different from the female gymnasts. Additionally, assessing the academic motivations of other collegiate athletes is needed. Do athletes who compete in both the fall and spring semesters have differing perspectives from those who only 
compete in one semester? These studies would provide additional insight into collegiate athletes' experiences and perspectives regarding academic motivation in and out of their competition seasons.

\section{Conclusion}

Based on the results of this study on academic motivations of MAC gymnasts, and if they differ in season compared to out of season, several conclusions can be made. Overall, it was concluded that while academic motivations in season and out of season differed, there was not one season that was more academically demanding than the other in terms of the academic expectations of both the athletes and the coaching staffs. Academic motivations of earning a high GPA, academic rewards systems, coaching staff support, decreasing stress, preparation for their future, and perfectionist tendencies were identified by the participating MAC gymnasts as being important to their academic careers.

It is important to note that while they reported feeling busier when they were in season, being busy was not found to concretely impact their academics in a negative way, but many identified feeling busy as actually increasing their focus and time management skills. Participants were also found to be motivated both in season and out of season by their own high expectations, coach's expectations, and need to decrease their stress levels, but were more motivated when in season to get ahead on their schoolwork to avoid having to focus on academics while traveling to away competitions. In order to improve their academic motivations and performance, administrators were given several suggestions, which if implemented into their programs, could assist in making a positive academic climate among their athletic teams at their respective university. 


\section{References}

Anshel, M.H., Henry, R., \& Kim, J.K. (2009). Reconceptualizing indicants of sport perfectionism as a function of gender. Journal of Sport Behavior, 32(4), 395-418.

Antonio Pineda-Espejel, H., Alarcón, E., Trejo, M., Chávez, C., \& Arce, R. (2016). Personal factors associated with pre-competitive anxiety in elite gymnasts. Science of Gymnastics Journal, 8(3), 271-281.

Buning, M.M., \& Thompson, M.A. (2015). Coaching behaviors and athlete motivation: Female softball athletes' perspectives. Sport Science Review, 24(5), 345-370.

Comeaux, E. (2011). A study of attitudes toward college student-athletes: Implications for faculty-athletics engagement. The Journal of Negro Education, 80(4), 521-532.

Davies, B., Nambiar, N., Hemphill, C., Devietti, E., Massengale, A., \& McCredie, P. (2015) Intrinsic motivation in physical education. Journal of Physical Education, Recreation \& Dance, 86(8), 8-13.

Gayles, J.G. (2009). The student athlete experience. New Directions for Institutional Research, $144,33-41$.

Gilman, R., \& Ashby, J.S. (2006). Perfectionism. In G.G. Bear, \& K.M. Minke (Eds.), Children's needs III: Development, prevention, and intervention (pp. 303-312). Bethesda, MD: National Association of School Psychologists.

Grasgreen, A. (2011). Near-rebuke of NCAA reforms. Retrieved January 31, 2018, from https://www.insidehighered.com/news/2011/11/02/panel-defends-athletes-says-ncaareforms-not-good-enough

Jang, B.G., Conradi, K., Mckenna, M.C., \& Jones, J.S. (2015). Motivation. The Reading Teacher, 69(2), 239-247.

LSDBi. (2018). Retrieved March 16, 2018, from https://web3.ncaa.org/lsdbi/search/proposalView?id=1765

NCAA. (2016). Results from the 2015 GOALS study of the student-athlete experience. Paper presented at the 2016 NCAA Convention, Indianapolis, IN. Retrieved from https://www.ncaa.org/sites/default/files/GOALS_convention_slidebank_jan2016_public. pdf

NCAA. (2017). 2017-2018 NCAA Division I manual. Indianapolis, IN.

NCAA. (2019). Student athletes. Retrieved from http://www.ncaa.org/student-athletes 
NCAA Academic Rankings. (2018). Retrieved from https://www.ncaagym.com/ncaa-academic-rankings/

Patton, M.Q. (2015). Qualitative research \& evaluation methods ( $4^{\text {th }}$ ed.). Thousand Oaks, CA: Sage.

Paule, A.L., \& Gilson, T.A. (2010). Current collegiate experiences of big-time, non-revenue, NCAA athletes. Journal of Intercollegiate Sport, 3, 333-347.

Paule, A.L., \& Gilson, T.A. (2011). Does athletic participation benefit or hinder academic performance: Non-revenue sport athlete experiences. Journal of Contemporary Athletics, 5(3), 203-217.

Pedersen, D.M. (2002). Intrinsic-extrinsic factors in sport motivation. Perceptual and Motor Skills, 95, 456-476.

Provencio, C. (2016). Student-athlete: A study of student-athlete workload compared with traditional student workload. (Order No. 10157496, South Dakota State University). ProQuest Dissertations and Theses, 65.

Saffici, C., \& Pellegrino, R. (1998). Intercollegiate athletics vs. academics: The student athlete or the athlete-student. Journal of Sports, 19, 1-6.

Simons, H.D., Van Rheenen, D., \& Covington, M.V. (1999). Academic motivation and the student athlete. Journal of College Student Development, 40(2), 151-161.

Vincent, W., \& Weir, J. (2012). Statistics in kinesiology (4th ed.). Champaign, IL: Human Kinetics. 